\title{
Perbandingan antara Visus Hasil Pemeriksaan Refraksi pada Tingkat Pencahayaan Optimal, Rendah, dan Tinggi \\ di Ruang Laboratorium Refraksi Optisi STIKes Dharma Husada Bandung
}

\author{
Suparni ${ }^{*}$, Benita Erma Indriani ${ }^{2}$ \\ ${ }^{1}$ Program Studi Sarjana Ilmu Kesehatan Masyarakat, STIKes Dharma Husada Bandung \\ ${ }^{2}$ Program Studi Diploma Tiga Refraksi Optisi, STIKes Dharma Husada Bandung \\ nsuparni@stikesdhb.ac.id
}

\begin{abstract}
ABSTRAK
Tajam penglihatan dipengaruhi oleh beberapa faktor yaitu usia, penerangan, silau, ukuran pupil, masa kerja, dan lama kerja. Tujuan penelitian untuk mengetahui perbedaan hasil pemeriksaan refraksi pada tiap tingkatan pencahayaan di ruang laboraturium refraksi optisi STIKes Dharma Husada Bandung Tahun 2019.

Rancangan penelitian adalah deskriptif, dengan melakukan pengukuran visus dasar dan visus koreksi pada tingkat pencahayaan optimal (300 lux), rendah (150 lux), dan tinggi (750 lux). Sampel penelitian ini menggunakan teknik accidental sampling, mahasiswa reguler Diploma III Refraksi Optisi STIKes Dharma Husada Bandung tingkat 1 dan 2 yang berjumlah 35 orang. Pengolahan data dilakukan secara otomatis, kemudian dianalisis secara univariat untuk melihat distribusi frekuensi variabel yang diteliti.

Dari hasil penelitian didapatkan perbandingan perbedaan visus dasar pada tingkat pencahayaan optimal, rendah dan tinggi adalah sebanyak $27 \%$. Perbandingan perbedaan visus koreksi pada tingkat pencahayaan optimal, rendah dan tinggi adalah sebanyak $25 \%$.

Penulis menyarankan pencahayaan di laboraturium harus dilakukan pembaharuan karena pencahayaan yang ada masih jauh dari standar untuk melakukan pemeriksaan refraksi.
\end{abstract}

Kata kunci : Perbandingan, Pencahayaan, Hasil Pemeriksaan Refraksi

\section{ABSTRACT}

Visual acuity are influenced by several factors such as age, lighting, glare, pupil size, working period, and duration of work. The purpose of the research was to determine the differences in the results of refraction test at each level of lighting in the refraction optic laboratory room of STIKes Bandung Dharma Husada in 2019.

The research's design was descriptive, with measurements visual acuity and visual correction at optimal (300 lux), low (150 lux), and high (750 lux) lighting levels. The sample of this research used accidental sampling technique, first and second grade regular students of Diploma III Refractionist Optician of STIKes Dharma Husada Bandung, amounting to 35 people. Data processing is done automatically, then analyzed univariately to see the distribution of the variables research.

The result found a comparison of visual acuity differences at optimal, low and high lighting levels is as much as 27\%. Comparison of differences in visual correction at optimal, low and high lighting levels is $25 \%$.

The writer recommends lighting in the laboratory to be renewed because the existing lighting is far from the standard for conducting refraction test.

Keywords : comparison, lighting, refraction test result 


\section{PENDAHULUAN}

Tajam penglihatan adalah istilah yang digunakan untuk menggambarkan kemampuan mata dalam membedakan detail objek (Keirl and Christie 2007). Tajam penglihatan dipengaruhi oleh beberapa faktor yaitu usia, penerangan, silau, ukuran pupil, masa kerja, dan lama kerja (Carlisle 2007; Suherman, Nurulita, and Astuti 2015). Sebagai seorang Refraksionis pemeriksaan refraksi dan pemeriksaan tajam penglihatan merupakan kompetensi dasar yang harus dimiliki. Pemeriksaan refraksi atau pemeriksaan tajam penglihatan merupakan kegiatan yang membutuhkan kontras tinggi dan membutuhkan pencahayaan yang stabil dan cukup untuk mendapatkan hasil maksimal. Semakin detail kegiatan yang dilakukan maka membutuhkan kontras yang tinggi dan semakin banyak pula pencahayaan yang diperlukan.

Pencahayaan yang terjadi diatas permukaan adalah kejadian cahaya yang menyentuh permukaan dengan satuan lumens per square meter (Skuta, Cantor, and Weiss 2010). Ruang pemeriksaan refraksi merupakan ruangan dengan tugas bekontras tinggi, menurut IES (Illuminating Engineering Society) ruangan dengan tugas berkontras tinggi memiliki rentang pencahayaan antara
200-300-500 lux. Pencahayaan yang terlalu tinggi akan membuat silau dan kehilangan bagian penting dari detail penglihatan (Bridger 2003). Pencahayaan yang baik adalah pencahayaan yang membuat pasien pemeriksaan refraksi dapat melihat obyek pada snellen chart secara jelas, cepat dan tanpa upaya-upaya yang tidak perlu Seperti, memincingkan mata atau mendongakkan badan kedepan untuk melihat objek.

Pencahayaan juga mempengaruhi besar dan kecilnya ukuran pupil, pengaturan refleks mata untuk mengatur cahaya yang masuk ke retina. Besar kecilnya ukuran pupil mempengaruhi penilaian visual acuity yang dipengaruhi oleh difraksi (Smith, Kincaid, and West 2002). Pada cahaya yang terang, iris berkontraksi dan membuat diameter pupil menjadi kecil. Ketika situasi ini terjadi, hanya bagian sentral dari lensa mata yang menerima bayangan objek yang sampai ke retina. Di cahaya yang redup, pupil melebar dan memperbanyak bagian lensa mata yang digunakan. Karena bagian peripheral lensa berfokus untuk menurunkan intensitas cahaya didepan bayangan pada bagian sentral (karakteristik dari lensa sederhana, dengan istilah "spherical aberration"), objek akan sedikit buram jika dilihat 
JURNAL SEHAT MASADA

VOLUME XIV

pada pencahayaan yang redup (Bridger 2003).

Ruang pemeriksaan dalam keadaan redup akan membuat ukuran pupil membesar, ukuran pupil yang besar megindikasikan bahwa mata bekerja untuk menerima cahaya lebih banyak. Jika pada saat mata dengan pupil yang besar dilakukan penilaian visual acuity maka akan membuat mata dua kali bekerja lebih keras untuk membandingkan objek pada snellen chart yang menyebabkan mata akan lebih cepat lelah. Pasien juga sulit dalam membandingkan objek dalam keadaan pencahayaan redup, objek yang sebenarnya terlihat menjadi buram atau bentuknya tidak jelas. Sedangkan jika pencahayaan terlalu tinggi membuat pupil mengecil untuk membuat cahaya yang masuk kedalam mata tidak berlebihan, pupil yang mengecil menyebabkan lensa mata berakomodasi untuk membuat bayangan tepat jatuh diretina, mata yang berakomodasi membuat perbedaan penilaian visual acuity atau pemeriksaan refraksi seseorang. Visual acuity dan pemeriksaan refraksi dilakukan pada saat lensa mata dalam keadaan tidak berakomodasi.

\section{JENIS PENELITIAN}

Penelitian ini menggunakan jenis deskriptif kuantitatif, dengan tujuan untuk
NOMOR 2 Juli 2020 ISSN : 1979-2344 mengukur perbandingan visus hasil pemeriksaan refraksi subjektif pada pencahayaan rendah, optimal, dan tinggi dengan objek snellen chart, pada jarak 6 meter. Subjeknya adalah mahasiswa Tingkat 1 \& 2 Program Studi Diploma Tiga Refraksi Optisi STIKes Dharma Husada Bandung, yang digunakan sebagai populasi atau sampel tertentu, pengumpulan data menggunakan instrumen penelitian, analisis data bersifat kuantitatif/statistic (Sugiyono 2014).

\section{PENDEKATAN WAKTU} PENGUMPULAN DATA

Dalam penelitian ini penulis menggunakan pendekatan waktu pengumpulan data cross sectional, dimana dalam mengukur variabel perbandingan visus hasil pemeriksaan refraksi subjektif pada tingkat pencahayaan tinggi, optimal, dan rendah di laboratorium Refraksi Optisi STIKes Dharma Husada Bandung Tahun 2019 dilakukan dalam satu saat, keduanya diukur secara bersamaan dalam satu waktu (Sugiyono 2017).

\subsection{Populasi dan Sample}

Populasi yang diteliti adalah mahasiswa Tingkat 1 dan 2 Program Studi Diploma Tiga Refraksi Optisi STIKes Dharma Husada Bandung sejumlah 80 orang, dengan teknik pengambilan sampel accidental sampling, didapat sample sebanyak 
JURNAL SEHAT MASADA

35 orang.

\subsection{Instrumen Penelitian}

Instrumen dalam penelitian ini menggunakan lembar observasi ketajaman penglihatan (visual acuity) yang berguna untuk menilai masingmasing hasil pemeriksaan ketajaman penglihatan pada mahasiswa tingkat 1 \& 2 Program Studi Diploma Tiga Refraksi Optisi STIKes Dharma Husada Bandung dengan membandingkan hasil pemeriksaan refraksi subjektif pada tingkat pencahayaan rendah, optimal, dan tinggi yang berfungsi sebagai alat atau fasilitas yang digunakan peneliti dalam mengumpulkan data agar pekerjaannya lebih mudah dan hasilnya lebih baik, dalam arti lebih cermat, lengkap dan sistematis sehingga lebih mudah diolah. (Sujarweni, 2014). Dan alat-alat yang dibutuhkan seperti trial lens set, trial frame, dan snellen chart.

\section{Metode Pengumpulan Data}

Pengumpulan data adalah suatu proses pendekatan suatu objek dan proses pengumpulan karakteristik subjek yang diperlukan dalam suatu penelitian (Notoatmodjo 2018).

Dalam penelitian ini, penulis menggunakan data primer untuk pengumpulan data. Data didapatkan melalui lembar observasi, hasil pemeriksaan
NOMOR 2 Juli 2020 ISSN : 1979-2344

refraksi subjektif pada pencahayaan rendah, optimal, dan tinggi menggunakan snellen chart dengan membandingkan visus awal dan visus akhir. Visus awal akan dilakukan pada tingkat pencahayaan tingi, optimal dan rendah, visus akhir juga akan dibandingkan pada tingkat pencahayaan tinggi, optimal dan rendah dengan besar koreksi yang sama. Pengambilan data didapatkan dari pemeriksaan yang langsung dilakukan dan didata kemudian diolah.

a. Pemeriksaan Refraksi Subjektif menggunakan Pencahayaan Optimal

1) Pemeriksaan dilakukan diruang dengan pencahayaan optimal (300 lux)

2) Dengan jarak objek (snellen chart) 6 meter dari depan pasien

3) Mengukur visus dasar

4) Menentukan BVS

5) Menentukan Titik akhir monokuler

b. Pemeriksaan Refraksi Subjektif menggunakan Pencahayaan Rendah

1) Pemeriksaan dilakukan diruang dengan pencahayaan rendah (150 lux)

2) Dengan jarak objek (snellen chart) 6 meter dari depan pasien

3) Mengukur kembali visus dasar dan membandingkan dengan visus dasar yang telah diukur saat pencahayaan optimal.

4) Membandingkan visus akhir (visus pada titik akhir monokuler) yang 
sudah dilakukan saat pencahayaan optimal dengan besar koreksi sama.

c. Pemeriksaan Refraksi Subjektif menggunakan Pencahayaan Tinggi

1) Pemeriksaan dilakukan diruang dengan pencahayaan rendah $(750$ $\operatorname{lux})$

2) Dengan jarak objek (snellen chart) 6 meter dari depan pasien

3) Mengukur kembali visus dasar dan membandingkan dengan visus dasar yang telah diukur saat pencahayaan optimal.

4) Membandingkan visus akhir (visus pada titik akhir monokuler) yang sudah dilakukan saat pencahayaan optimal dengan besar koreksi sama.

\section{Teknik Pengolahan dan Analisa Data}

Dalam penelitian, data yang diperoleh masih mentah, belum memberikan informasi apa-apa, dan belum siap untuk disajikan. Karena hal itu, maka pengolahan data penting dilakukan untuk memperoleh penyajian data sebagai hasil yang berarti dan kesimpulan yang baik (Notoatmodjo 2018).

a. Teknik Pengolahan Data

Data yang diperoleh harus melalui pengolahan data dengan tahapan sebagai berikut (Notoatmodjo 2018).

1) Editing (Penyunting)

Data yang diperoleh harus melaui penyuntingan terlebih dahulu.
Penyuntingan sendiri merupakan kegiatan untuk pengecekan dan perbaikan isian lembar observasi tersebut. Dimana jika ada kesalahan penulisan pada visus diperbaiki dengan visus yang sebenarnya.

2) Coding (Pengkodean)

Setelah penyuntingan, maka dilakukan pengkodean, pengkodean ini sangat bermanfaat untuk proses pemasukan data. Pengkodean data yaitu mata responden, mata kanan dan mata kiri dengan responden yang sama memiliki kode yang sama.

3) Entry (Pemasukan) / processing

Setelah data melalui proses pengkodean, kemudian dilanjutkan dengan memasukan data yang berbentuk kode angka/ huruf tadi kedalam peogram atau software komputer pengolah data.

4) Cleaning (Pengecekan)

Setelah seluruh data dimasukan kedalam program pengolah data tersebut, perlu dilakukan pengecekan kembali. Hal ini dilakukan untuk menghindari kemungkinan kesalahan kode, ketidaklengkapan dan lain sebagainya, kemudian dilakukan pembetulan atau koreksi pada datadata yang salah. Kesalahan penulisan pemasukan data akan dicek dan diperbaiki misalnya kesalahan 
ISSN : 1979-2344

penulisan visus responden.

b. Analisis Data

1) Statistik Deskriptif

Statistik deskriptif adalah statistik yang digunakan untuk menganalisis data dengan cara mendeskripsikan atau menggambarkan data yang telah terkumpul sebagaimana adanya tanpa bermaksud membuat kesimpulan yang berlaku untuk umum atau generalisasi. Dalam statistik deskriptif juga dapat dilakukan mencari kuatnya hubungan antara variabel melalui analisis korelasi, melakukan prediksi dengan menggunakan program softwear komputer, dan membuat perbandingan dengan membandingan rata-rata data sampel atau populasi (Sugiyono, 2015).

Tabel 1. Distribusi Frekuensi Gambaran Perbandingan Visus Dasar dengan Tingkat Pencahayaan Optimal, Rendah, dan Tinggi

\begin{tabular}{|c|c|c|c|c|c|c|}
\hline \multirow{2}{*}{$\begin{array}{l}\text { No } \\
\text { Res }\end{array}$} & \multirow[b]{2}{*}{$\mathrm{OD} / \mathrm{OS}$} & \multicolumn{3}{|c|}{ Visus Dasar } & \multirow{2}{*}{ Perbedaan } & \multirow{2}{*}{ Diagnosa } \\
\hline & & $\begin{array}{c}\text { Pencahayaan } \\
\text { Optimal }\end{array}$ & $\begin{array}{l}\text { Pencahayaan } \\
\text { Rendah }\end{array}$ & $\begin{array}{c}\text { Pencahayaan } \\
\text { Tinggi }\end{array}$ & & \\
\hline \multirow[t]{2}{*}{1} & OD & $6 / 6$ & $6 / 6$ & $6 / 6$ & 0 & Emetropia \\
\hline & OS & $6 / 6$ & $6 / 6$ & $6 / 6$ & 0 & Emetropia \\
\hline \multirow[t]{2}{*}{2} & OD & $6 / 6$ & $6 / 6$ & $6 / 6$ & 0 & Emetropia \\
\hline & OS & $6 / 6$ & $6 / 6$ & $6 / 6$ & 0 & Emetropia \\
\hline \multirow[t]{2}{*}{3} & OD & $6 / 6$ & $6 / 6$ & $6 / 6$ & 0 & Emetropia \\
\hline & OS & $6 / 6$ & $6 / 6$ & $6 / 6$ & 0 & Emetropia \\
\hline \multirow[t]{2}{*}{4} & OD & $6 / 6$ & $6 / 6$ & $6 / 6$ & 0 & Emetropia \\
\hline & OS & $6 / 6$ & $6 / 6$ & $6 / 6$ & 0 & Emetropia \\
\hline \multirow[t]{2}{*}{5} & OD & $6 / 6$ & $6 / 6$ & $6 / 6$ & 0 & Emetropia \\
\hline & OS & $6 / 6$ & $6 / 6$ & $6 / 6$ & 0 & Emetropia \\
\hline \multirow{2}{*}{6} & OD & $6 / 6$ & $6 / 6$ & $6 / 6$ & 0 & Emetropia \\
\hline & OS & $6 / 6$ & $6 / 6$ & $6 / 6$ & 0 & Emetropia \\
\hline \multirow[t]{2}{*}{7} & OD & $6 / 60$ & $6 / 60$ & $6 / 60$ & 0 & Emetropia \\
\hline & OS & $6 / 60$ & $6 / 60$ & $6 / 60$ & 0 & Emetropia \\
\hline \multirow[t]{2}{*}{8} & OD & $6 / 9$ & $6 / 12$ & $6 / 9$ & 1 & Ametropia \\
\hline & OS & $6 / 9$ & $6 / 12$ & $6 / 9$ & 1 & Ametropia \\
\hline \multirow[t]{2}{*}{9} & OD & $6 / 6$ & $6 / 6$ & $6 / 6$ & 0 & Emetropia \\
\hline & OS & $6 / 6$ & $6 / 6$ & $6 / 6$ & 0 & Emetropia \\
\hline \multirow[t]{2}{*}{10} & OD & $6 / 6$ & $6 / 6$ & $6 / 6$ & 0 & Emetropia \\
\hline & OS & $6 / 6$ & $6 / 6$ & $6 / 6$ & 0 & Emetropia \\
\hline \multirow[t]{2}{*}{11} & OD & $6 / 6$ & $6 / 6$ & $6 / 6$ & 0 & Emetropia \\
\hline & OS & $6 / 6$ & $6 / 6$ & $6 / 6$ & 0 & Emetropia \\
\hline \multirow[t]{2}{*}{12} & OD & $6 / 9$ & $6 / 12$ & $6 / 9$ & 1 & Ametropia \\
\hline & OS & $6 / 12$ & $6 / 15$ & $6 / 12$ & 1 & Ametropia \\
\hline \multirow[t]{2}{*}{13} & OD & $6 / 6$ & $6 / 6$ & $6 / 6$ & 0 & Emetropia \\
\hline & OS & $6 / 6$ & $6 / 6$ & $6 / 6$ & 0 & Emetropia \\
\hline \multirow[t]{2}{*}{14} & OD & $6 / 7.5$ & $6 / 9$ & $6 / 7.5$ & 1 & Ametropia \\
\hline & OS & $6 / 9$ & $6 / 9$ & $6 / 9$ & 0 & Ametropia \\
\hline \multirow[t]{2}{*}{15} & OD & $6 / 6$ & $6 / 6$ & $6 / 6$ & 0 & Emetropia \\
\hline & OS & $6 / 6$ & $6 / 6$ & $6 / 6$ & 0 & Emetropia \\
\hline 16 & OD & $6 / 6$ & $6 / 6$ & $6 / 6$ & 0 & Emetropia \\
\hline
\end{tabular}




\begin{tabular}{|c|c|c|c|c|c|c|}
\hline & OS & $6 / 9$ & $6 / 12$ & $6 / 9$ & 1 & Ametropia \\
\hline \multirow[t]{2}{*}{17} & OD & $6 / 6$ & $6 / 6$ & $6 / 6$ & 0 & Emetropia \\
\hline & OS & $6 / 6$ & $6 / 6$ & $6 / 6$ & 0 & Emetropia \\
\hline \multirow[t]{2}{*}{18} & OD & $6 / 6 \mathrm{f} 2$ & $6 / 7.5$ & $6 / 6$ & 1 & Emetropia \\
\hline & OS & $6 / 6$ & $6 / 6$ & $6 / 6$ & 0 & Emetropia \\
\hline \multirow[t]{2}{*}{19} & OD & $6 / 15$ & $6 / 20$ & $6 / 15$ & 1 & Ametropia \\
\hline & OS & $6 / 15$ & $6 / 20$ & $6 / 15$ & 1 & Ametropia \\
\hline \multirow[t]{2}{*}{20} & OD & $6 / 6$ & $6 / 6$ & $6 / 6$ & 0 & Emetropia \\
\hline & OS & $6 / 6$ & $6 / 6$ & $6 / 6$ & 0 & Emetropia \\
\hline \multirow[t]{2}{*}{21} & OD & $6 / 6$ & $6 / 6$ & $6 / 6$ & 0 & Emetropia \\
\hline & OS & $6 / 6$ & $6 / 6$ & $6 / 6$ & 0 & Emetropia \\
\hline \multirow[t]{2}{*}{22} & OD & $6 / 6$ & $6 / 6$ & $6 / 6$ & 0 & Emetropia \\
\hline & OS & $6 / 6$ & $6 / 6$ & $6 / 6$ & 0 & Emetropia \\
\hline \multirow[t]{2}{*}{23} & OD & $6 / 6 \mathrm{f} 1$ & $6 / 7.5$ & $6 / 6$ & 1 & Emetropia \\
\hline & OS & $6 / 6$ & $6 / 6$ & $6 / 6$ & 0 & Emetropia \\
\hline \multirow[t]{2}{*}{24} & OD & $6 / 6$ & $6 / 6$ & $6 / 6$ & 0 & Emetropia \\
\hline & OS & $6 / 6$ & $6 / 6$ & $6 / 6$ & 0 & Emetropia \\
\hline \multirow[t]{2}{*}{25} & OD & $6 / 6$ & $6 / 6$ & $6 / 6$ & 0 & Emetropia \\
\hline & OS & $6 / 6$ & $6 / 6$ & $6 / 6$ & 0 & Emetropia \\
\hline \multirow[t]{2}{*}{26} & OD & $6 / 15$ & $6 / 20$ & $6 / 15$ & 1 & Ametropia \\
\hline & OS & $6 / 9$ & $6 / 12$ & $6 / 9$ & 1 & Ametropia \\
\hline \multirow[t]{2}{*}{27} & OD & $6 / 7.5$ & $6 / 12$ & $6 / 7.5$ & 1 & Ametropia \\
\hline & OS & $6 / 7.5$ & $6 / 9$ & $6 / 7.5$ & 1 & Ametropia \\
\hline \multirow[t]{2}{*}{28} & OD & $6 / 6$ & $6 / 6$ & $6 / 6$ & 0 & Emetropia \\
\hline & OS & $6 / 6$ & $6 / 6$ & $6 / 6$ & 0 & Emetropia \\
\hline \multirow[t]{2}{*}{29} & OD & $6 / 60$ & $5 / 60$ & $6 / 60$ & 1 & Ametropia \\
\hline & OS & $5 / 60$ & $4 / 60$ & $5 / 60$ & 1 & Ametropia \\
\hline \multirow[t]{2}{*}{30} & OD & $6 / 6$ & $6 / 6$ & $6 / 6$ & 0 & Emetropia \\
\hline & OS & $6 / 6$ & $6 / 6$ & $6 / 6$ & 0 & Emetropia \\
\hline \multirow[t]{2}{*}{31} & OD & $5 / 60$ & $5 / 60$ & $5 / 60$ & 0 & Ametropia \\
\hline & OS & $5 / 60$ & $5 / 60$ & $5 / 60$ & 0 & Ametropia \\
\hline \multirow[t]{2}{*}{32} & OD & $6 / 9 \mathrm{f} 1$ & $6 / 12$ & $6 / 9$ & 1 & Ametropia \\
\hline & OS & $6 / 6$ & $6 / 6$ & $6 / 6$ & 0 & Emetropia \\
\hline \multirow[t]{2}{*}{33} & OD & $6 / 6$ & $6 / 7.5$ & $6 / 7.5$ & 1 & Emetropia \\
\hline & OS & $6 / 6$ & $6 / 6$ & $6 / 6$ & 0 & Emetropia \\
\hline \multirow[t]{2}{*}{34} & OD & $6 / 6$ & $6 / 6$ & $6 / 6$ & 0 & Emetropia \\
\hline & OS & $6 / 6$ & $6 / 7.5$ & $6 / 6$ & 1 & Emetropia \\
\hline \multirow[t]{2}{*}{35} & OD & $6 / 6$ & $6 / 6$ & $6 / 6$ & 0 & Emetropia \\
\hline & OS & $6 / 6$ & $6 / 6$ & $6 / 6$ & 0 & Emetropia \\
\hline & \multirow{2}{*}{\multicolumn{2}{|c|}{ Total Perbedaan }} & & Ya & & \\
\hline & & & & Tidak & & \\
\hline & \multicolumn{2}{|c|}{ Total Mata } & & 70 Mata & & \\
\hline
\end{tabular}

Berdasarkan tabel 1 diketahui bahwa perbandingan perbedaan visus dasar pada tingkat pencahayaan optimal, rendah dan tinggi sebanyak 19 mata dengan persentase sebanyak $27 \%$. 


\section{Tabel 2 Distribusi Frekuensi Gambaran Hasil Refraksi pada Tingkat Pencahayaan Optimal}

\begin{tabular}{cccc}
\hline No. & Diagnosa Refraksi & F & \% \\
\hline 1 & Emmetropia & 50 & 71.4 \\
2 & Ammetropia & 20 & 28.6 \\
\hline Total & & 70 & 100.0 \\
\hline
\end{tabular}

Berdasarkan tabel 2 diketahui bahwa pada pencahayaan optimal responden yang mengalami emmetropia sebanyak 50 mata dengan persentase $71.4 \%$. Dan responden yang mengalami ammetropia sebanyak 20 mata dengan persentase $28.6 \%$

Tabel 3 Distribusi Frekuensi Gambaran Hasil Refraksi pada Tingkat Pencahayaan Rendah

\begin{tabular}{cccc}
\hline No. & Diagnosa Refraksi & F & \% \\
\hline 1 & Emmetropia & 46 & 65.7 \\
2 & Ammetropia & 24 & 34.3 \\
\hline Total & & 70 & 100.0 \\
\hline
\end{tabular}

Berdasarkan tabel 3 diketahui bahwa pada pencahayaan rendah responden yang mengalami emmetropia sebanyak 46 mata dengan persentase $65.7 \%$. Dan responden yang mengalami ammetropia sebanyak 24 mata dengan persentase $34.3 \%$

Tabel 4 Distribusi Frekuensi Gambaran Hasil Refraksi pada Tingkat Pencahayaan Tinggi

\begin{tabular}{cccc}
\hline No. & Diagnosa Refraksi & F & \% \\
\hline 1 & Emmetropia & 49 & 70 \\
2 & Ammetropia & 21 & 30 \\
\hline Total & & 70 & 100.0 \\
\hline
\end{tabular}

Berdasarkan tabel 4 diketahui bahwa pada pencahayaan tinggi responden yang mengalami emmetropia sebanyak 49 mata dengan persentase 70\%. Dan responden yang mengalami ammetropia sebanyak 21 mata dengan persentase $30 \%$.

\section{DAFTAR PUSTAKA}

Bridger, Robert. 2003. Engineering Introduction to Egonomics.

Carlisle, Brian. 2007. "Fitting The Task to the Man: A Textbook of Occupational Ergonomics, 4th Edition. By E. Grandjean (Taylor \& Francis, 1988.) [Pp. $x+363$.] Price: $£ 3000$ (Hardback), £1350 (Paperback)." International Journal of Production Research.

Keirl, Andrew, and Caroline Christie. 2007. Clinical Optics and Refraction A Guide for Optometrists, Contact Lens Opticians and Dispensing Opticians. 1st ed. eds. Andrew Keirl and Caroline Christie. London UK: Elsevier.

Notoatmodjo, Soekidjo. 2018. Metodologi Penelitian Kesehatan. Jakarta: Rineka Cipta. 
Skuta, G L, L B Cantor, and J S Weiss. 2010.

Basic and Clinical Science Course Section 3, 2010-2011: Clinical Optics. Amer Academy of Ophthalmology. https://books.google.co.id/books?id=TiC 7cQAACAAJ.

Smith, M E, M C Kincaid, and C E West. 2002. Basic Science, Refraction, and Pathology. Mosby.

https://books.google.co.id/books?id=4uh qAAAAMAAJ.

Sugiyono. 2014. "Metode Penelitian Kombinasi (Mixed Methods)." Bandung:
Alfabeta.

. 2017. CV Alfabeta Statistika Untuk Penelitian. Bandung: Penerbit Alfabeta. ed. Endang Mulyatiningsih. Bandung: CV Alfabeta.

Suherman, Agus, Ulfa Nurulita, and Rahayu Astuti. 2015. "Hubungan Intensitas Penerangan, Masa Kerja, Dan Lama Kerja Dengan Ketajaman Penglihatan.” Jurnal Kesehatan Masyarakat Indonesia 10(2): 10-17.

https://jurnal.unimus.ac.id/index.php/jkm i/article/view/2380/2353. 